\title{
O cinema a serviço da educação: a experiência das escolas de ensino básico e secundário no Algarve
}

Ana Catarina Pereira

Jornalista, investigadora do Labcom, doutoranda em Ciências da Comunicação na Universidade da Beira Interior - Covilhã, Portugal.

E-mail: anacatarinapereira4@gmail.com

Resumo: Primeiro se estranha, depois se entranha. Assim se poderia definir, recorrendo a Fernando Pessoa, o primeiro contato de uma criança ou adolescente com o cinema que não faz parte do circuito comercial. Preparar o espectador para a visualização de obras que requerem uma análise cuidada e uma interpretação profunda é o papel dos professores que, de alguma forma, influenciam a vida e os gostos daqueles com quem contatam. À necessidade de formação destes profissionais, associa-se a dificuldade de transposição de burocracias e preconceitos instituídos que continuam a condicionar a introdução do cinema nos programas de ensino básico e secundário. No Algarve, a região mais ao sul de Portugal Continental, o projeto Juventude Cinema Escola, coordenado por Graça Lobo, adquiriu uma notoriedade e seriedade contracorrentes.

Palavras-chave: Cinema, educação, espectador, programa JCE, análise crítica.
Abstract: First you will find it strange, but then you interiorize it. This is how we could define, using Fernando Pessoa, the first contact of a child or adolescent with the non-blockbuster cinema. Train the spectator to watch films that require careful consideration and a thorough interpretation - that is the role of teachers that, somehow, influence the lives and tastes of those with whom they contact. The need for training these professionals is associated with the difficulty of over passing established bureaucracies and prejudices that continue to constrain the introduction of cinema in the programs of basic and secondary education. In Algarve, the southernmost region of Portugal, the Youth Film School project (Juventude Cinema Escola), coordinated by Graça Lobo, has acquired a reputation and seriously counter-currents.

Keywords: Cinema, education, spectator, JCE program, critic analysis.

Eu acredito que o filme está destinado a revolucionar nosso sistema educacional e que em poucos anos este suplantará largamente, se não totalmente, o uso de livros didáticos. Devo dizer que, em média, temos cerca de dois por cento de eficiência dos livros de escola, como eles são escritos hoje. A educação do futuro, a meu ver, será realizada por meio do filme... onde deverá ser possível obter cem por cento de eficiência (Thomas Edison) ${ }^{1}$. 


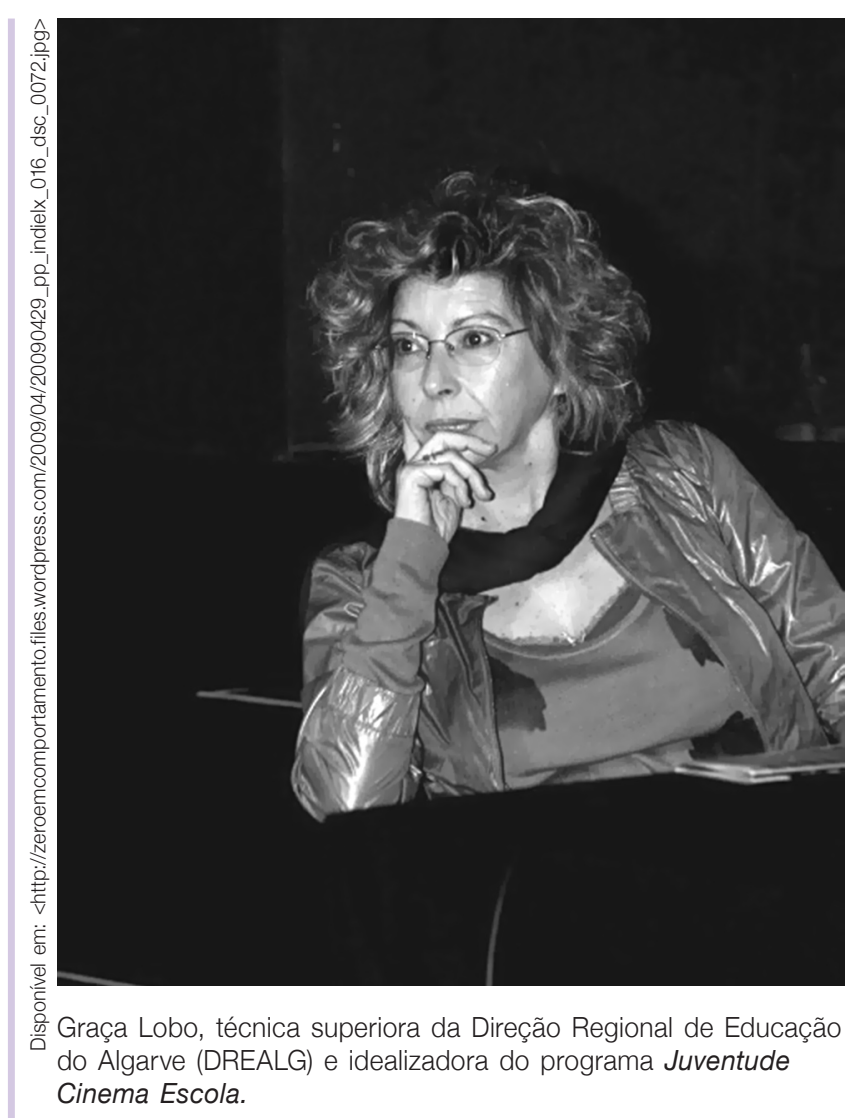

A defesa da introdução de programas de análise e produção cinematográfica nos períodos de escolaridade obrigatória é uma causa antiga, que conhece um crescente número de adeptos em Portugal. Para além do cultivo e refinamento do olhar de jovens espectadores, a introdução de novas metodologias de ensino associadas aos audiovisuais poderá ainda comportar outras vantagens. Entre elas, referimos a pressão sobre distribuidores para que outros tipos de cinema cheguem às salas comerciais, bem como um maior interesse dos espectadores por um cinema de autor que contraria a lógica dos meios de comunicação contemporâneos, a profusão de imagens por segundo e os hipnotizantes efeitos especiais que reservam pouco espaço à introspecção.

Na opinião de José Luís Tornel Sala, um sistema educativo que procure decodificar e analisar criticamente os discursos audiovisuais (tanto do cinema como da televisão) deve ser prioritário para o Estado, de tal forma que, afirma,

Los poderes públicos debieran ser capaces de potenciar el conocimiento profundo del lenguaje fílmico en el alumnado, porque sólo la aprehensión de este tipo de conceptos, en una sociedad mediatizada como nunca por los mass-media, por el poder e influjo de la imagen, deviene esencial para conseguir ciudadanos críticos, no fácilmente manipulables ideológica, actitudinal y conductalmente ${ }^{2}$.

O autor defende assim, tal como outros autores que enumera (Saturnino

2. SALA, José Luis Tornel. Cine formativo mediante enseñanza por tareas: milagro en Milan (Cinema formativo através de aprendizagem por tarefas: milagre em Milão). Revista Escuela Abierta, Andalucía CEU - Fundación San Pablo, n. 10, p. 274, 2007 Disponível em: <http:// www.ceuandalucia.com/ escuelaabierta/pdf/articulos_ea10/14Tornel.pdf>. de La Torre e Avelina Escudero), que o cinema, de uma perspectiva formativa, é capaz de transmitir valores culturais, sociais e educativos que potenciam o desenvolvimento humano e a melhoria do comportamento social.

Consciente do importante papel dos educadores neste ciclo, Graça Lobo concebeu um projeto que começou por aplicar, em termos práticos, no distrito de Faro - Portugal. O seu objetivo inicial consistiu em levar o cinema às escolas da região; fazer as crianças vibrarem com a magia da sétima arte, fascinarem-se pelos filmes de Chaplin e Godard, ou mesmo se interessarem por cinema português. Passado pouco tempo, pôs mãos à obra e reuniu as ferramentas necessárias para concretizar o objetivo. Atualmente, vários estabelecimentos de 
ensino, dos mais cosmopolitas aos do interior serrano, aderiram ao programa Juventude Cinema Escola, que foi crescendo e tomando proporções inesperadas.

\section{O SURGIMENTO DO PROJETO}

Para conhecermos melhor este programa, consideramos importante desvendar os principais passos do percurso profissional de Graça Lobo. Em 1980 licenciou-se em História, pela Faculdade de Letras de Lisboa, tendo começado por dar aulas no ensino secundário. Mais tarde, participou em programas de formação para professores, iniciando desta forma novos projetos que a levariam a abandonar o ensino tradicional. Já em 2008 aceitou o convite para ser técnica superiora da Direção Regional de Educação do Algarve (DREALG), função que ainda hoje desempenha. Sendo mestre em Gestão Cultural pela Universidade do Algarve (em parceria com a Universidade Paris 8), iniciou este ano o doutoramento na mesma área.

A ideia de levar o cinema às escolas surgiu precisamente do fato de Graça Lobo ter sido professora do ensino secundário durante cerca de vinte anos. Pela experiência acumulada, acabaria por constatar que o cinema entrou na sala de aula, sobretudo, a partir da década de 1990, de uma forma que classifica como meramente instrumental. Segundo a própria, os professores passaram então a utilizar alguns filmes como complemento dos conteúdos programáticos, principalmente nas disciplinas de História e Filosofia. Por outro lado, e em paralelo com a sua atividade como professora, Graça Lobo esteve sempre

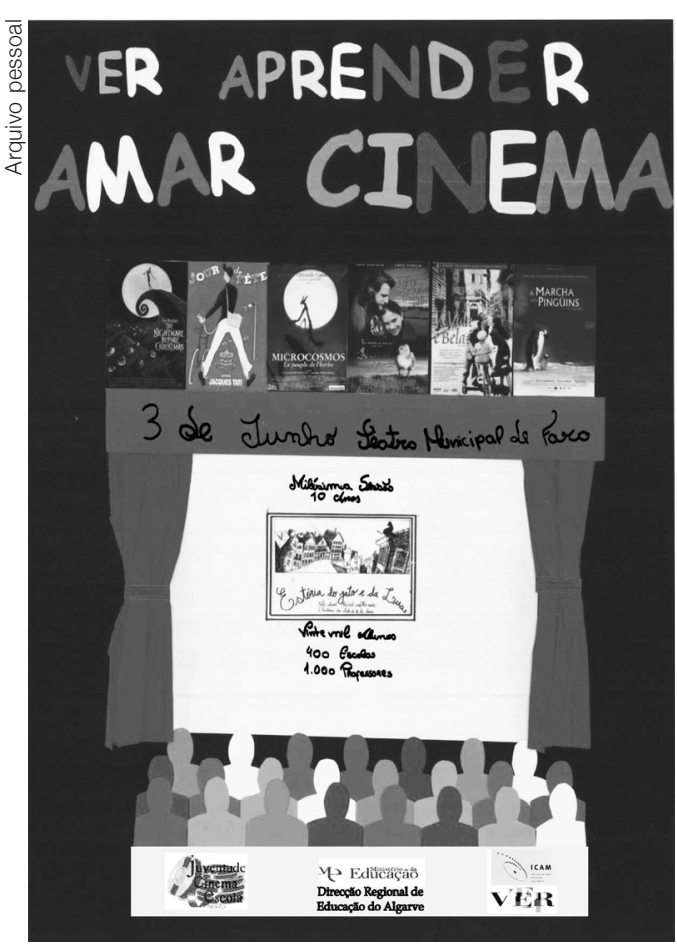

Cartaz elaborado por alunos do 6o ano da Escola EB2/3 Nuno Mergulhão, em Portimão, Portugal. associada às iniciativas promovidas pelo Cineclube de Faro, pelo que pensou em criar um programa que permitisse aos alunos ter uma relação mais estreita com a sétima arte. $\mathrm{Na}$ sua opinião, era importante que os estudantes do ensino básico e secundário pudessem conhecer a linguagem do cinema e que isso lhes permitisse ter outra visão do mundo.

A concretização dos planos viria a suceder-se em meados da década de 1990 e de uma forma relativamente rápida, quando frequentava o mestrado em Gestão Cultural e, simultaneamente, realizava um estágio em Paris. Teve então um primeiro contato com o programa francês Escolas ao Cinema, sendo que, mais tarde, estagiou também na Cinemateca Portuguesa. Todo este percurso levou-a a apresentar a 
comunicação \& educação • Ano XVI • número 1 • jan/jun 2011

3. PEREIRA, Ana Catarina. A "stôra" que leva o cinema à escola. Revista Notícias Sábado, n. 250 (publicada com os jornais Diário de Notícias e Jorna de Notícias, propriedade do grupo Controlinveste, 23 out. 2010).

4. PEREIRA, cit.

5. Ibid.

6 lbid. proposta de criar um programa didático de cinema à Direção Regional de Educação do Algarve. O diretor regional, que era então António Pina, aderiu imediatamente e, no ano escolar de 1997/1998, iniciaram uma experiência-piloto: foram programadas algumas sessões e realizado um estudo da adesão dos professores ao projeto. Segundo Graça Lobo, constatou-se que havia um grande interesse por parte destes, embora a maioria tivesse admitido que não tinha qualquer tipo de formação na área.

No ano letivo seguinte, o programa decolou oficialmente, com a prévia realização de sessões formativas e de esclarecimento para os professores. Em seguida, os principais intervenientes neste projeto perceberam que, para que o trabalho tivesse uma lógica e um significado contundentes, não bastava conduzir os alunos, pontualmente, a uma sala de cinema: "Tudo isto tinha que ter uma estrutura mais sequencial”, afirma Graça Lobo, que, em parceria com a colega Anabela Moutinho, procurou aprofundar o programa.

De início, e sendo que a técnica superior da DREALG já conhecia programas semelhantes que tinham sido implementados noutros países do mundo, tentou adaptar-se ao modelo preexistente ao Algarve, "com marcas pessoais e jogando com os constrangimentos que existem em Portugal, sobretudo no nível da exibição de filmes" ${ }^{\prime \prime}$. Segundo afirma, foram então contatados distribuidoras e exibidores, bem como os ajustes definitivos para o início do projeto: "No fundo, criamos uma rede de cumplicidades". Financeiramente, o projeto foi apoiado pelo Instituto do Cinema e do Audiovisual (ICA) desde o ano letivo 1998/1999, embora nos últimos três anos isso já não tenha sido possível, por alterações legislativas recentemente produzidas. Durante o ano letivo de 2000/2001, foram também apoiados pela Fundação Calouste Gulbenkian.

\section{AS ATIVIDADES COM OS ALUNOS}

Depois de visualizarem o filme, os alunos preenchem uma ficha. Mais tarde, durante uma aula, fazem uma espécie de correção dessa ficha, com uma montagem em DVD, para aclarar os conhecimentos: "Imaginemos, por exemplo, que queremos que eles compreendam o conceito de grande plano; nessa montagem voltamos a mostrar onde estava e para que foi utilizado. Tudo isto é feito de uma forma sequencial e gradativa, dos conceitos elementares para os mais complexos" ${ }^{\prime 6}$ explica Graça Lobo.

No final do ano, todos os alunos têm uma ficha sintética de aquisição de conhecimentos, e uma ficha qualitativa, para que os professores percebam o que acharam do programa, quais os filmes de que mais gostaram e se pretendem ou não prosseguir para o próximo nível. Segundo a técnica superiora da DREALG, em geral, há uma percentagem absolutamente residual de alunos que respondem negativamente. Todos os outros passam para o nível seguinte.

Muito para além destas fichas, os jovens estudantes fazem também outro tipo de trabalhos sobre os filmes que viram: em alguns casos chegam mesmo a realizar pequenos filmes que são avaliados por um júri e premiados nas festas 
de final do ano letivo. Também podem apresentar outro modo de participações, como coreografias, peças de teatro ou momentos musicais. Jogam muitas vezes um quiz show que se chama A febre do cinema, com uma equipe de cada escola, o que, segundo Graça Lobo, é sempre muito divertido e dinâmico. Nos últimos dois anos, têm sido desenvolvidas mais duas iniciativas que obtiveram bastante adesão: uma delas chama-se Vou levar os meus pais ao cinema, o que inverte os papéis tradicionais; e a outra foi denominada Ver para ler, desenvolvida em parceria com a rede de bibliotecas escolares, tendo como objetivo trabalhar a ligação íntima entre cinema e literatura. O objetivo é simplesmente o de ler mais: mais imagens e mais livros.

\section{METAS A ATINGIR}

Em termos gerais, o programa JCE apresenta os seguintes objetivos:

- testar a capacidade de observação;

- implementar a análise dos filmes;

- conhecer a linguagem técnica e a história do cinema;

- promover a avaliação dos filmes;

- reconhecer o cinema como meio de comunicação;

- problematizar o cinema como expressão artística;

- promover a interdisciplinaridade e o trabalho de projeto.
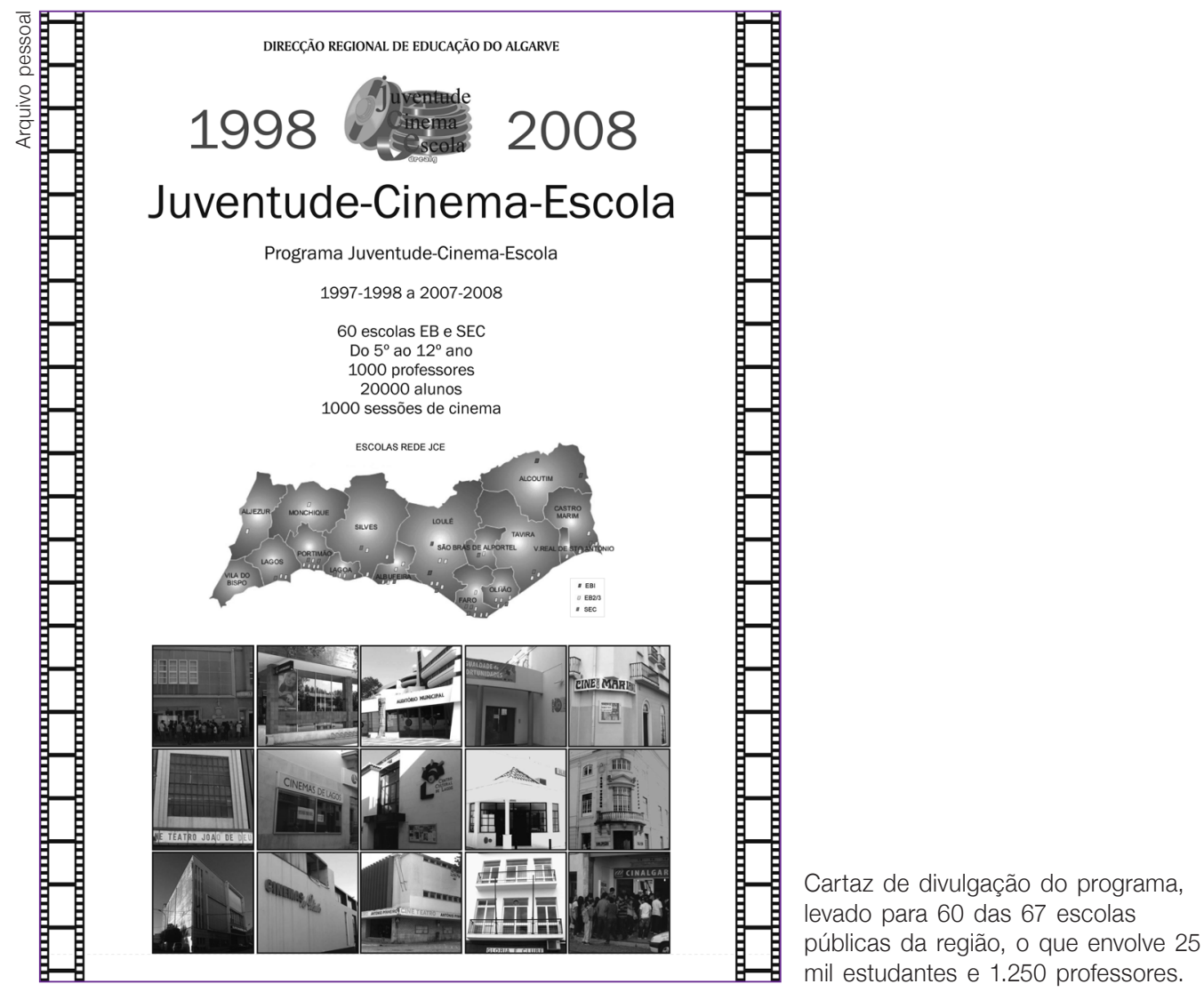
Em termos técnicos, o JCE traduz-se no ensino sistemático e sequencial de um programa de conteúdos temáticos (abordáveis em várias disciplinas) e cinematográficos (linguagem, técnicas, história, profissões), num curso de cinco níveis para escolas EB (do $5^{\circ}$ ao $9^{\circ}$ ano de escolaridade) e num curso de três níveis para escolas secundárias (do $10^{\circ}$ ao $12^{\circ}$ anos de escolaridade), a lecionar a partir dos filmes vistos (quatro sessões por ano letivo) ${ }^{7}$.

As escolas interessadas no programa realizam as candidaturas no início de cada ano escolar, na pessoa dos próprios professores que, sem exceções à regra, poderão ser de qualquer disciplina. Os filmes, por sua vez, devem ser trabalhados de uma forma interdisciplinar, como na Área de Projeto, por exemplo. Como garante Graça Lobo, não há nenhum constrangimento em envolver, por exemplo, o professor de Educação Física: "Já tivemos alguns, embora reconheçamos que a maioria, no segundo e terceiro ciclos, são de Português, História e Educação Visual. Já no ensino secundário, o programa é habitualmente impulsionado pelos professores de Filosofia, História de Arte ou de disciplinas relacionadas com as novas tecnologias".

\section{OS FILMES SELECIONADOS}

Os filmes são escolhidos tendo em conta o nível etário dos alunos, embora se procure excluir aqueles que provavelmente já foram vistos em casa - na televisão, em DVD, ou noutros formatos. Por esta razão, são normalmente evitados filmes de proveniência norte-americana (a não ser que sejam, de alguma forma, alternativos).

Neste aspecto, uma das expectativas de Graça Lobo é que as crianças e adolescentes venham a ter um papel mais ativo na sociedade, contrariando a lógica da distribuição. E isto se traduz em exemplos concretos, já que recorda com especial carinho um dos dias em que, estando a dar uma aula em Lagos, tentava explicar aos alunos como funcionam as distribuidoras em Portugal. Ao abrirem o jornal para ver os filmes que estavam passando nas salas de cinema mais próximas, rapidamente concluíram que apenas eram exibidos filmes norte-americanos, até que começaram a questionar: "Professora, o que é que nós podemos fazer para ver outros filmes? Estamos fartos de ver sempre as mesmas coisas!" 9 .

A cada nível escolar corresponde um filme que faz parte da história do cinema. Estes são, segundo Graça Lobo, os mais difíceis de escolher, por já não se encontrarem disponíveis em película. Dentro das escassas possibilidades existentes, os alunos assistem, no quinto ano, ao clássico Carrossel da Esperança (Jacques Tati - 1949); no sexto ano veem Dançando na chuva (Gene Kelly e

7. DREALG. Disponível em: <http://www.drealg. min-edu.pt/>.

8. PEREIRA, cit. 9. Ibid. Stanley Donen - 1952); no sétimo ano é exibido Cinema Paradiso (Giuseppe Tornatore - 1988); no oitavo, Tempos modernos (Charles Chaplin - 1936), e no nono ano, $O$ grande ditador (Charles Chaplin - 1940). No décimo ano é exibido O Encouraçado Potemkin (Sergei Eisenstein - 1925), embora pensem em mudar, 
uma vez que foi detectada certa dificuldade de recepção por parte dos alunos. No décimo primeiro ano passa Psicose (Alfred Hitchcock - 1960) e no décimo segundo, Acossado (Jean-Luc Godard - 1960).

Por outro lado, tendo estes alunos idades particularmente marcantes em termos de construção e assimilação de valores, é também notável uma preocupação com a mensagem social que os filmes transmitem. Como afirma Graça Lobo, os objetivos do programa são claros no nível social e afetivo:

Há um conjunto de filmes que espelham esses valores, como o Billy Elliot (Stephen Daldry - 2000), em que se trabalha a tolerância e o preconceito. Outro filme que os alunos adoram é A vida é bela (Roberto Benigni - 1997), e que muitas vezes os leva a ler o próprio Diário de Anne Frank. Eles são particularmente sensíveis às questões da guerra e da paz - $O$ grande ditador, por exemplo, também permite este tipo de reflexão ${ }^{10}$.

Para além destas, existem outras sessões. "Os filmes que eles veem na sala de cinema são estes, mas depois nós sugerimos muitos outros que complementam os temas, e que eles podem ver na escola em formato DVD"11, acrescenta Graça Lobo. Em muitas escolas já se formaram clubes de cinema que exibem filmes às quartas-feiras, à tarde. Para além das inúmeras vantagens já enunciadas, esta parece ser também uma forma de angariar espectadores para o cinema português. Segundo Graça Lobo, o intuito é sempre inverter as ideias estereotipadas sobre cinema português, mostrando a sua diversidade. São passados muitos curtas-metragens e animações de realizadores nacionais. "Muitas vezes, podem até mesmo contar com a presença dos próprios, que falam com os alunos", costuma exemplificar a coordenadora do programa.

Em conclusão, o balanço que faz destes doze anos de cinema nas escolas algarvias não poderia ser mais positivo. A equipe coordenada por Graça Lobo já trabalhou com 60 das 67 escolas públicas da região, o que envolve $25 \mathrm{mil}$ estudantes e 1.250 professores. Muitos deles fazem hoje parte do movimento cineclubista, ou frequentam licenciaturas e mestrados de cinema. Apesar de satisfeita com os resultados, Graça Lobo começou já a traçar novas metas, procurando estender o programa a todo o país. O slogan que apregoa, e que deu mote à concretização deste sonho, parece assim estar a difundir-se: Ver, aprender e amar cinema. Como, novamente, Thomas Edison fez questão de afirmar: "We can teach almost anything with motion pictures" (Nós podemos ensinar quase tudo com os filmes) $)^{12}$.

\section{REFERÊNCIAS BIBLIOGRÁFICAS}

CUBAN, Larry. Teachers and machines (Os professores e as máquinas). New York: Teachers College Press, 1986.

PEREIRA, Ana Catarina. A "stôra" que leva o cinema à escola. Revista Notícias Sábado, n. 250 (publicada com os jornais Diário de Notícias e Jornal de Notícias, propriedade do grupo Controlinveste, 23 out. 2010).
10. Ibid.

11. Ibid.

12. WISE, Harry A. Motion pictures as an aid in teaching American History (Os filmes como um auxílio no ensino da História americana). Yale: University Press/New Haven, 1939. p. 1. 
WISE, Harry A. Motion pictures as an aid in teaching American History (Os filmes como um auxílio no ensino da História americana). Yale: University Press/New Haven, 1939.

\section{Endereços eletrônicos}

DIRECÇÃO Regional de Educação do Algarve. Disponível em: <http://www. drealg.min-edu.pt/>.

LOBO, Graça. Por dentro do filme: o cinema na sala de aula, 2005. ACTAS DO III SOPCOM, VI LUSOCOM e II IBÉRICO - Volume IV. Disponível em: <http:/ / www.bocc.uff.br/pag/lobo-graca-dentro-filme-cinema-sala-aula.pdf $>$.

SALA, José Luis Tornel. Cine formativo mediante enseñanza por tareas: milagro en Milan (Cinema formativo através de aprendizagem por tarefas: milagre em Milão). Revista Escuela Abierta, Andalucía: CEU - Fundación San Pablo, n. 10, 2007. Disponível em: <http://www.ceuandalucia.com/escuelaabierta/pdf/ articulos_ea10/14Tornel.pdf>. 